\title{
The Changes of Theoretical Wave Power from Offshore to Coast in the South-western Black Sea
}

\author{
Ajab Gul Majidi ${ }^{1}$, Bilal Bingölbali ${ }^{1}$, and Adem Akpınar, ${ }^{1, *}$ \\ ${ }^{1}$ Bursa Uludağ University, Civil Engineering Department, 16059 Bursa, Turkey
}

\begin{abstract}
This study concentrates on the changes of theoretical wave power from offshore to coastal regions of south-western Black Sea. The investigation also offers a long-term (31-year) wave power quantification analysis between 1979 and 2009 using the SWAN version 41.01AB numerical wave model. The wave resource assessment is performed in terms of its seasonal and monthly variability of wave power, annual wave power directional distributions and the comparison of the maximum and median values of some important wave power parameters in the west of Istanbul a major city in Turkey that straddles Europe and Asia across the Bosphorus Strait. For this analysis, 10 point locations distributed on two perpendicular lines (KA and KE) to the coastline with five different depths $(5,25,50,75$, and $100 \mathrm{~m}$ ) in the areas of interest were selected. The data needed was extracted from the dataset produced by $[1,2]$ using a calibrated nested layered wave hindcast model SWAN forced with CFSR winds. The results show that the wave energy resource in the study area is high, and the potential locations can be considered for extracting wave electrical power.
\end{abstract}

\section{Introduction}

By the time energy demand is increasing very fast on the earth, if we do not find various clean energy resource options, fossil energy will cause lots of negative impacts on the environment. One of these impacts is the greenhouse gasses, which is a fatal warning for lives on the earth. The power in the ocean waves is a very good candidate to become one of the options of future renewable energy. The ocean wave power is a vast clean energy source, but it's very new and under investigation. If we look back to twenty years ago, the wind energy was in the same place as ocean wave energy is today. The most familiar and common method to extract energy is using steam and turbine mechanism. The only problem to extract the huge wave electrical power is designing a suitable technology for wave power. A lot of research companies and universities nowadays are working hard to solve this problem. There are many prototype wave energy farms working nowadays, but they are not commercial yet. Another essential aspect for extracting wave power is to investigate the interested geographical locations to have some ideas about the status of waves and the wave power, the continuity, or the variability of wave power distribution in time. It's also very important to choose the most energetic place with the lowest variability in wave power seasonally and annually. The characteristics mentioned above are investigated in five different depths from very deep water to very shallow water (shoreline).

\section{Study area and the wave data}

The Black Sea is located between $40^{\circ} .56^{\prime}-46^{\circ} .33 \mathrm{~N}^{\prime}$ latitudes and $27^{\circ} .27^{\prime}-41^{\circ} .42^{\prime} \mathrm{E}$ Longitudes. It has 461000 $\mathrm{km}^{2}$ surface area, including the Azov Sea, with a 0.55 million $\mathrm{km}^{3}$ water volume. The Black Sea has a total of $8350 \mathrm{~km}$ of coast length, with approximately $1300 \mathrm{~m}$ mean and $2588 \mathrm{~m}$ maximum water depth. This study focuses on the high energy potential areas (the southwest) of the Black Sea [2]. The 31-year (1979-2009) long-term estimations of wave parameters along the south-west coast of the Black Sea were produced for every location under our previous TUBITAK Project [3] are extracted from the database of intense wind and wave data for each location. This data set was produced using a three nested grid system, which contains a coarse grid including all of the Black Sea, a fine grid including the western Black Sea, and a sub-grid domain including near Karaburun in the south-west of the Black Sea. In this layered nested grid system, waves are firstly generated on a regular computational domain which covers the entire Black Sea; then calculations are made on a finer regular grid covering the western part of the Black Sea with boundary conditions from the previous regular grid domain which covered all the Black Sea. Finally, with the boundary conditions provided by this fine domain, a long-term wave database is created in a high-resolution sub-grid domain Karaburun. Detailed information on the calibration and verification of the coarse grid can be found in [1]. Furthermore, although

Corresponding author: ademakpinar@uludag.edu.tr 
an article on the detailed calibration and verification of the nested grid system is already published [4], the initial findings are presented in a conference paper [5]. Therefore, all the wave parameters needed for each location from this specified data set are taken for 31 years (1979-2009) at a time resolution of 2 hours. The bathymetry, fine grid, and nested domain Karaburun are shown in Fig.1.

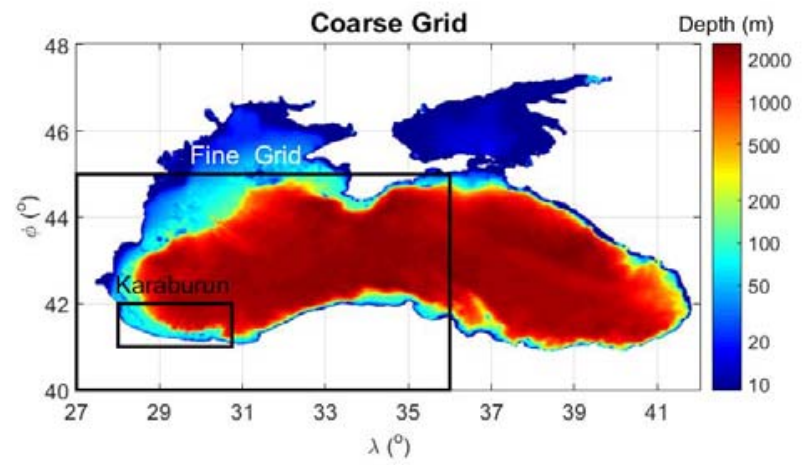

Fig. 1. The bathymetry map of the Black Sea, The coarse grid, Fine grid, and sub-domain Karaburun.

The bathymetry for the wind-wave modeling of the Black Sea was obtained from General Bathymetric Charts of Oceans [6], which is prepared by The British Oceanographic Data Center (BODC). The resolution of latitude and longitude was $0.008333^{\circ}$. For the forcing of the SWAN model, the CFSR winds [7] at $10 \mathrm{~m}$ above the surface of the water with a spatial resolution of $0.3125^{\circ}$ and a time resolution of $1 \mathrm{hr}$ was used. The coordinates and depth of the chosen 10 locations in the study area are given in Table 1.

Table 1. The coordinates and depth of the chosen locations in the study area

\begin{tabular}{ccccc}
\hline Location & Location ID & $\mathbf{X p}\left(^{\mathbf{0}}\right)$ & $\mathbf{Y p}\left(\mathbf{(}^{\mathbf{0}}\right)$ & Depth(m) \\
\hline KA1 & 1 & 28.0625 & 41.8913 & 4.1 \\
KA2 & 2 & 28.0938 & 41.8913 & 25.2 \\
KA3 & 3 & 28.1250 & 41.8913 & 54.3 \\
KA4 & 4 & 28.2437 & 41.8913 & 74.8 \\
KA5 & 5 & 28.5688 & 41.8913 & 99.5 \\
KE1 & 6 & 30.3188 & 41.2043 & 7.2 \\
KE2 & 7 & 30.3188 & 41.2174 & 25.9 \\
KE3 & 8 & 30.3188 & 41.2348 & 50.8 \\
KE4 & 9 & 30.3188 & 41.3000 & 75.7 \\
KE5 & 10 & 30.3188 & 41.3348 & 99.3 \\
\hline
\end{tabular}

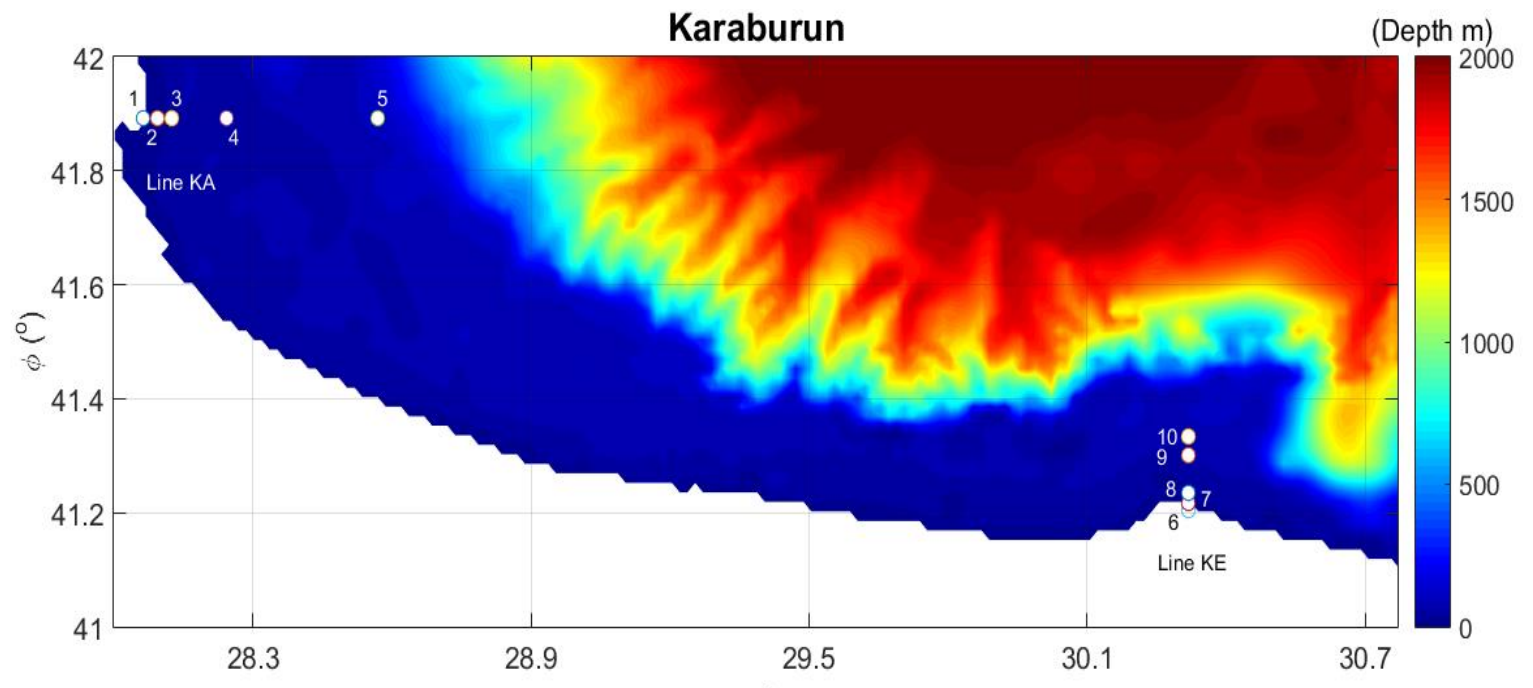

Fig. 2. The sub-domain Karaburun with the selected 10 locations on two perpendicular lines to the coastline 
As the water density is 800 times more than air, sea waves have the highest energy density among the other renewable energy resources. Prof. Salter from the University of Edinburgh under the lab conditions has shown that it's possible to convert more than $81 \%$ of wave energy into electricity [8]. The wave power is calculated with the following equation.

$P_{w}=\frac{\rho g^{2} T_{e} H_{s}^{2}}{64 \pi}$

In the above equation, $\mathrm{P}_{\mathrm{w}}$ is wave power in deep water, $\rho$ is water density $\left(1030 \mathrm{~kg} / \mathrm{m}^{3}\right), \mathrm{g}$ is gravity constant $\left(9.81 \mathrm{~m} / \mathrm{s}^{2}\right), T_{e}$ is wave energy period, and $H_{s}$ is the significant wave height [9].

\section{Results}

The mean annual wave power at every location is given in Table 2. If we compare the first 5 locations which are located on the line KA, the mean wave power is almost three times higher than the locations on the line KE. Thus, in Karaburun for establishing a wave energy converting farm, the line KA is the possible choice.

Table 2. 31-year long-term annual mean wave power at all selected locations

\begin{tabular}{cccc}
\hline Location & $\begin{array}{c}\text { Annual Mean } \\
\text { Power (kW/m) }\end{array}$ & Location & $\begin{array}{c}\text { Annual Mean } \\
\text { Power (kW/m) }\end{array}$ \\
\hline KA1 & 2.62 & KE1 & 1.87 \\
KA2 & 5.67 & KE2 & 2.40 \\
KA3 & 6.34 & KE3 & 2.67 \\
KA4 & 7.18 & KE4 & 2.90 \\
KA5 & 8.29 & KE5 & 3.03 \\
\hline
\end{tabular}

In order to have an idea about the wave power variability in 31-year long-term wave analysis, the monthly and seasonal wave power variability indices (Fig. 3) are calculated with the following equation.

$V_{i}=\frac{\left(P_{w \max }-P_{w \min }\right)}{P_{\text {wmean }}}$



Fig. 3. Seasonally and monthly wave power variability indices at all the selected locations

As it was expected, the locations with the lowest depth have the most moderate variability in wave power. It is also seen that seasonally variability is lower in comparison with the monthly variability.
Another important parameter which is investigated in here is the directional distribution of wave power (wave power roses). The annual wave power roses of all selected locations are shown in Fig. 4.

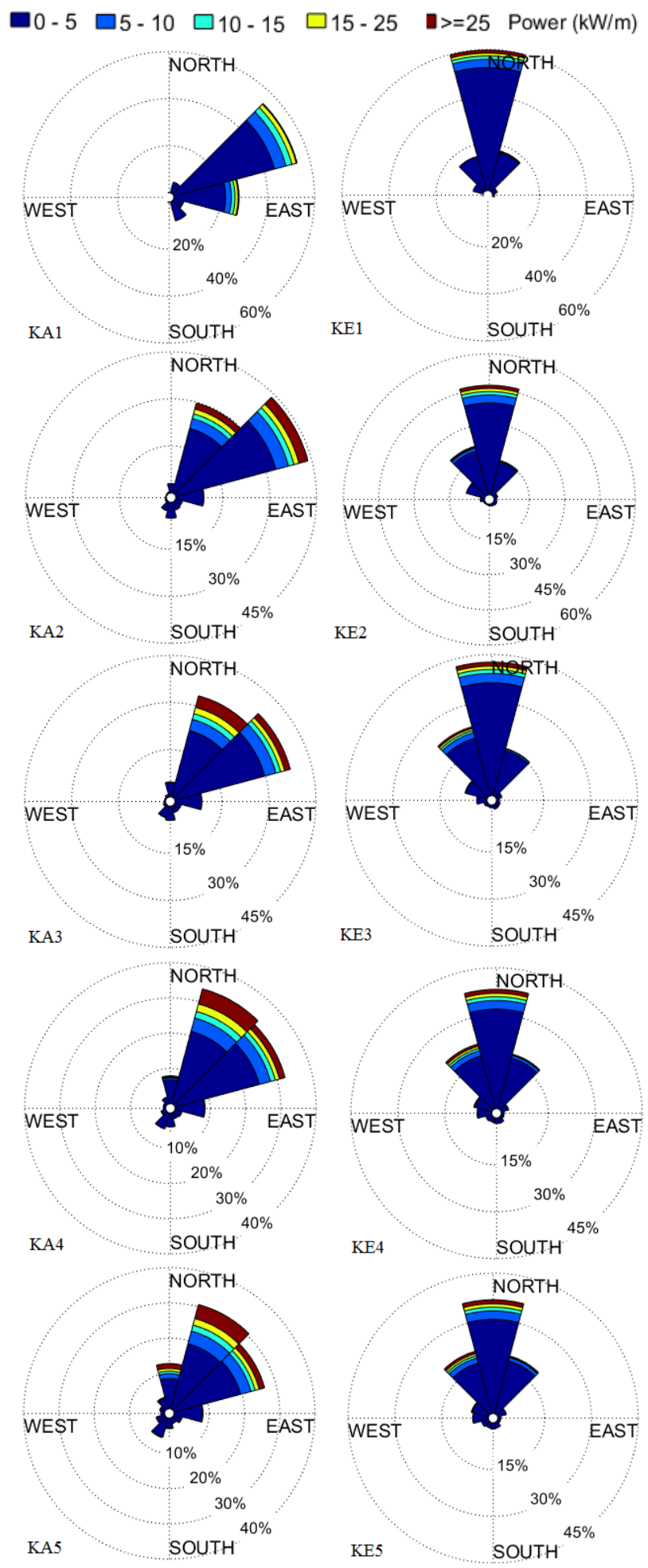

Fig. 4. Wave power roses. The five locations of the line KA are in the left column, and the five locations of line $\mathrm{KE}$ are in the right column of the figure.

According to the wave power roses in Fig. 4, the dominant annual wave direction for the locations on the Line KA is between NNE-NEE, and for the locations on the Line KE, the wave direction varies between NNW-NE. 
Median and maximum values for the main wave parameters in the Karaburun computational domain for 10 locations in two different lines perpendicular to the coastline as the result of the SWAN simulation performed in a 31-year time period (1979-2009) in Table 3. The comparison of the main wave parameters for winter and summer median values in the Karaburun computational domain for 10 locations in two different lines perpendicular to the coastline as resulting of SWAN simulation performed in a 31-year time period (19792009 are given in Table 4.

Table 3. Annual median and maximum values for the main wave parameters in the Karaburun computational domain for all the selected locations

\begin{tabular}{|c|c|c|c|c|c|c|}
\hline Locations & $\begin{array}{c}\mathbf{H}_{\text {smed }} / \mathbf{H}_{\text {smax }} \\
\text { (m) }\end{array}$ & $\begin{array}{c}\mathbf{T}_{\text {emed }} / \mathbf{T}_{\text {emax }} \\
\text { (s) }\end{array}$ & $\begin{array}{c}\mathbf{T}_{\text {pmed }} / \mathbf{T}_{\text {pmax }} \\
\text { (s) }\end{array}$ & $\begin{array}{c}\mathbf{P}_{\text {wmed }} / \mathbf{P}_{\text {wmax }} \\
(\mathbf{k W} / \mathbf{m})\end{array}$ & $\begin{array}{c}\text { DIR }_{\text {med }} \\
\left({ }^{\circ}\right)\end{array}$ & $\begin{array}{c}\mathbf{E}_{\text {med }} / \mathbf{E}_{\max } \\
(\mathrm{kW} / \mathbf{m} * \mathbf{h r})\end{array}$ \\
\hline KA1 & $0.5 / 2.6$ & $4.4 / 12.8$ & $3.3 / 10.3$ & $0.6 / 41.8$ & 198.7 & $1.1 / 83.6$ \\
\hline KA2 & $0.7 / 9.6$ & $4.1 / 12.7$ & $3.1 / 10.5$ & $0.9 / 564.0$ & 215.6 & $1.8 / 1128.0$ \\
\hline KA3 & $0.7 / 10.1$ & $4.1 / 12.5$ & $3.1 / 10.3$ & $0.9 / 608.7$ & 218.4 & $1.9 / 1217.4$ \\
\hline KA4 & $0.7 / 11.1$ & $4.1 / 12.3$ & $3.1 / 10.3$ & $1 / 721.3$ & 221.3 & $2.1 / 1442.5$ \\
\hline KA5 & $0.8 / 12.8$ & $4.1 / 12.7$ & $3.2 / 10.9$ & $1.2 / 1015.3$ & 224.5 & $2.5 / 2030.7$ \\
\hline KE1 & $0.4 / 4.4$ & $3.8 / 13.7$ & $2.9 / 11.4$ & $0.3 / 130.4$ & 270.9 & $0.6 / 260.7$ \\
\hline KE2 & $0.5 / 9.8$ & $3.8 / 13.6$ & $2.8 / 10.9$ & $0.4 / 637.0$ & 276.2 & $0.8 / 1274.0$ \\
\hline KE3 & $0.5 / 10.1$ & $3.7 / 13.5$ & $2.8 / 10.8$ & $0.4 / 658.8$ & 276.2 & $0.9 / 1317.6$ \\
\hline KE4 & $0.5 / 10.3$ & $3.7 / 13.1$ & $2.8 / 10.4$ & $0.5 / 667.0$ & 273.1 & $1 / 1334.0$ \\
\hline KE5 & $0.5 / 10.7$ & $3.7 / 13.1$ & $2.8 / 10.4$ & $0.5 / 719.1$ & 271.8 & $1 / 1438.1$ \\
\hline
\end{tabular}

Table 4. Comparison of median values of the main wave parameters for winter and summer in the Karaburun computational domain for all the selected locations

\begin{tabular}{|c|c|c|c|c|c|c|c|c|c|c|}
\hline \multirow{2}{*}{$\begin{array}{c}\text { Locations } \\
\text { No } \\
\end{array}$} & Winter & Summer & Winter & Summer & Winter & Summer & Winter & Summer & Winter & Summer \\
\hline & \multicolumn{2}{|c|}{$\mathbf{H}_{\mathrm{s} \text { med }}(\mathbf{m})$} & \multicolumn{2}{|c|}{$T_{\mathrm{e} \text { med }}(\mathbf{s})$} & \multicolumn{2}{|c|}{$\mathrm{T}_{\mathrm{p} \text { med }}(\mathrm{s})$} & \multicolumn{2}{|c|}{$P_{w \text { med }}(\mathrm{kW} / \mathrm{m})$} & \multicolumn{2}{|c|}{$\operatorname{DIR}_{\text {med }}\left({ }^{\circ}\right)$} \\
\hline KA1 & 0.58 & 0.51 & 4.50 & 4.15 & 3.31 & 3.16 & 0.73 & 0.50 & 200.5 & 200.2 \\
\hline KA2 & 0.77 & 0.65 & 4.22 & 4.03 & 3.17 & 3.12 & 1.20 & 0.81 & 222.2 & 216.3 \\
\hline KA3 & 0.80 & 0.66 & 4.23 & 4.02 & 3.17 & 3.11 & 1.30 & 0.84 & 226.9 & 218.4 \\
\hline KA4 & 0.89 & 0.68 & 4.25 & 4.01 & 3.28 & 3.10 & 1.58 & 0.89 & 231.4 & 221.5 \\
\hline KA5 & 1.00 & 0.71 & 4.37 & 4.00 & 3.43 & 3.12 & 2.07 & 0.98 & 235.7 & 225.6 \\
\hline KE1 & 0.45 & 0.44 & 4.30 & 3.56 & 3.32 & 2.77 & 0.42 & 0.34 & 274.2 & 265.6 \\
\hline KE2 & 0.56 & 0.49 & 4.22 & 3.60 & 3.15 & 2.76 & 0.61 & 0.42 & 281.8 & 268.9 \\
\hline KE3 & 0.61 & 0.50 & 4.18 & 3.58 & 3.11 & 2.73 & 0.70 & 0.42 & 282.9 & 269.0 \\
\hline KE4 & 0.67 & 0.51 & 4.09 & 3.54 & 3.07 & 2.69 & 0.86 & 0.44 & 279.1 & 267.3 \\
\hline KE5 & 0.70 & 0.52 & 4.09 & 3.53 & 3.08 & 2.67 & 0.95 & 0.46 & 277.1 & 266.2 \\
\hline
\end{tabular}

Annual and seasonal mean and maximum wave power changes from 1979 to 2009 are respectively given in Fig 5 and Fig 6 at location KA5. The same figures for the other locations will be presented in the PowerPoint presentation.

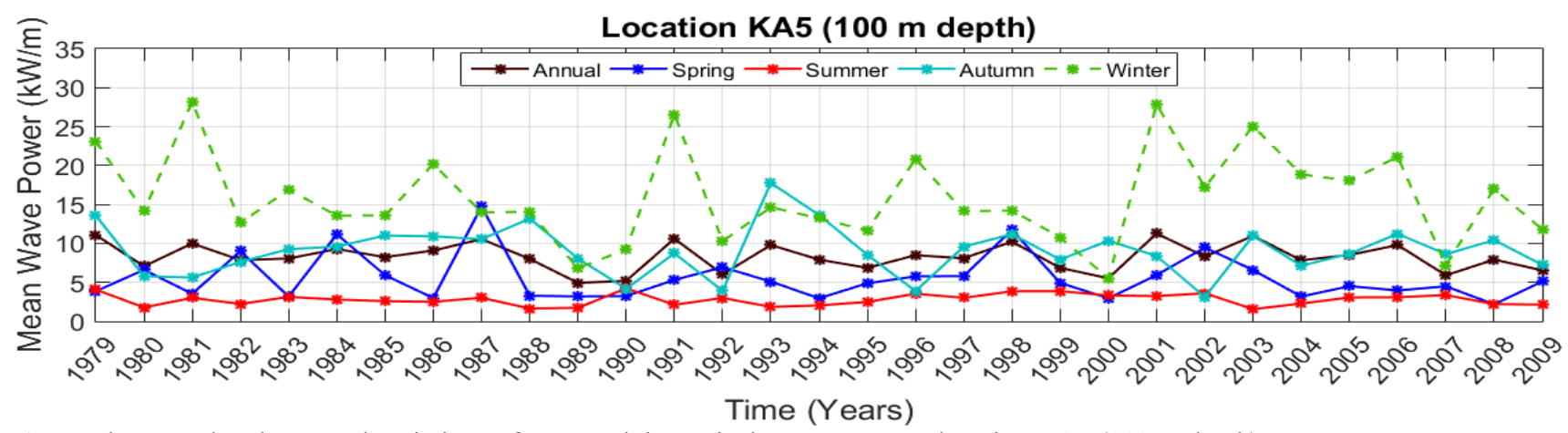

Fig. 5. The annual and seasonal variations of averaged theoretical wave power at location KA5 (100 m depth).



Fig. 6. The annual and seasonal changes of maximum theoretical wave power at location KA5 (100 m depth). 
In Table 3, site KA5 (100 $\mathrm{m}$ depth) reports an average annual median of $0.8 \mathrm{~m}$ with a maximum of $12.8 \mathrm{~m}$ wave height and the mean annual median theoretical wave power of this site is $1.2 \mathrm{~kW} / \mathrm{m}$ with a maximum of 1015 $\mathrm{kW} / \mathrm{m}$ in the long-term 31-year wave hindcast which present it as the most energetic location in the area. The seasonal statistics of the analysis in Table 4 also show KA5 as the best choice for the extraction of wave energy in the interest area. The mean seasonal wave power potential at location KA5 is the highest for winter with three peak values in 1981,1991 , and 2001, with the two lowest values in 1989 and 2000 along the long-term 31 year period in Fig. 5. Summer presents the lowest wave power potential. The annual and winter maximum values of wave power potential report the highest values in 2004 and the lowest value in 1990 (Fig. 6).

\section{Conclusion}

The development of renewable energy plays a vital role in a country. Therefore, in order to contribute to the development of renewable energies, all local resources need to be evaluated in detail. Wave energy is one of the uncovered energy treasures that can make a significant positive change in electrical power. Currently, the potential of uncovered wave energy in Turkish coastlines of the Black Sea is not investigated enough. Thus, in order to enhance the light on convertible wave power in the south-western coasts of the Black Sea, a 31 year (1979-2009) wave power resource assessment was presented in this research work. An appropriate nearshore numerical model was used in a three-level (Coarse grid, Fine grid, and high-resolution Sub-grid) nested layered mode to hindcast the ocean waves' energy resource levels. The study investigated the theoretical wave power, annual variations of wave power, and the power roses, which shows the direction of force by the use of statistical indices, which can interpret the available power resources and their variations clearly. In SWAN analysis coarse mesh gives the vital information as input to fine mesh and the fine mesh gives the inputs to the finest grid (sub-domain), and the nested high-resolution sub-domain provides the important wave parameters like significant wave height $\left(\mathrm{H}_{\mathrm{s}}\right), \mathrm{T}_{\mathrm{m}-02}$ mean wave period, $\mathrm{T}_{\mathrm{m}-10}$ wave energy period, etc. for all the study area spatially and interested locations. The results show that the wave energy resource in the study area is high, and the potential locations can be considered for extracting wave electrical power. For example, the average annual theoretical wave power at location KA5 (Depth $100 \mathrm{~m}$, Land distance $40 \mathrm{~km}$ ) is $8.3 \mathrm{~kW} / \mathrm{m}$ while the mean significant wave height is $1.14 \mathrm{~m}$, and the maximum significant wave height is changing between $6-13 \mathrm{~m}$.

The wave resource of the study area can be considered significant and can be studied in detail on the applicability of wave energy resource applications.
Medium range scaled wave energy converters, which are based on significant wave height and wave period of a long term examination of the resource, can deliver reliable electrical power, can be adapted to the area.

The authors want to thank TÜBİTAK (The Scientific and Technological Research Council of Turkey) for supporting this study with the present research project No. 118R024 and the previous research project No. 214M436 within the scope of the Scientific and Technological Research Projects (1001) Program.

\section{References}

1. A. Akpınar, B. Bingölbali, G.Ph. Van Vledder, Ocean Eng., 126, 276-298 (2016).

2. Bingölbali, B., Wave climatology, and development of a wave hindcast model with the nested grid system for the south-western coasts of the Black Sea, MSc Thesis, Uludağ University, Bursa, Turkey (2018).

3. A. Akpınar, S. Bekiroğlu, G.Ph. Van Vledder, B. Bingölbali, H. Jafali, “Temporal and Spatial Analysis of Wave Energy Potential Along the South-western Coasts of the Black Sea (TUBITAK Project)" Project No: 214M436 (2015).

4. B. Bingölbali, A. Akpınar, H. Jafali, G. Ph. Van Vledder, Ocean Eng., 172, 31-45 (2019).

5. A. Akpınar, B. Bingölbali, H. Jafali, Wave Hindcasting for Wave Energy Assessments in the Black Sea, International Conference on Engineering and Natural Sciences (ICENS2016), Sarajevo, Bosnia-Herzegovina (2016).

6. GEBCO, British Oceanographic Data Center, Centenary Edition of the GEBCO Dijital Atlas [CDROM]. Published on behalf of the Intergovernmental Oceanographic Commission and the International Hydrographic Organization, Liverpool, (2014).

7. Saha, S., Moorthi, S., Pan, H.-L., Wu, X., Wang, J., Nadigai, S., Tripp, P., Kistler, R., Woollen, J., Behringer, D., Liu, H., Stokes, D., Grumbine, R., Gayno, G., Wang, J., Hou, Y.-T., Chuang, H.-Y., Juang, H.-M.H., Sela, J., Iredell, M., Treadon, R., Kleist, D., van Delst, P., Keyser, D., Derber, J., Ek, M., Meng, J., Wei, H., Yang, R., Lord, S., van den Dool, H., Kumar, A., Wang, W., Long, C., Chelliah, M., Xue, Y., Huang, B., Schemm, J.-K., Ebisuzaki, W., Lin, R., Xie, P., Chen, M., Zhou, S., Higgins, W., Zou, C.- Z., Liu, Q., Chen, Y., Han, Y., Cucurull, L., Reynolds, R.W., Rutledge, G., Goldberg, G., Bull. Am. Meteorol. Soc. 91, 1015-1057 (2010).

8. http://synergyfiles.com/2016/05/formula-calculatingwave-power/, (2016)

9. D. Silva, E. Rusu, C. G. Soares, Energies., 6, 13441364 (2013). 